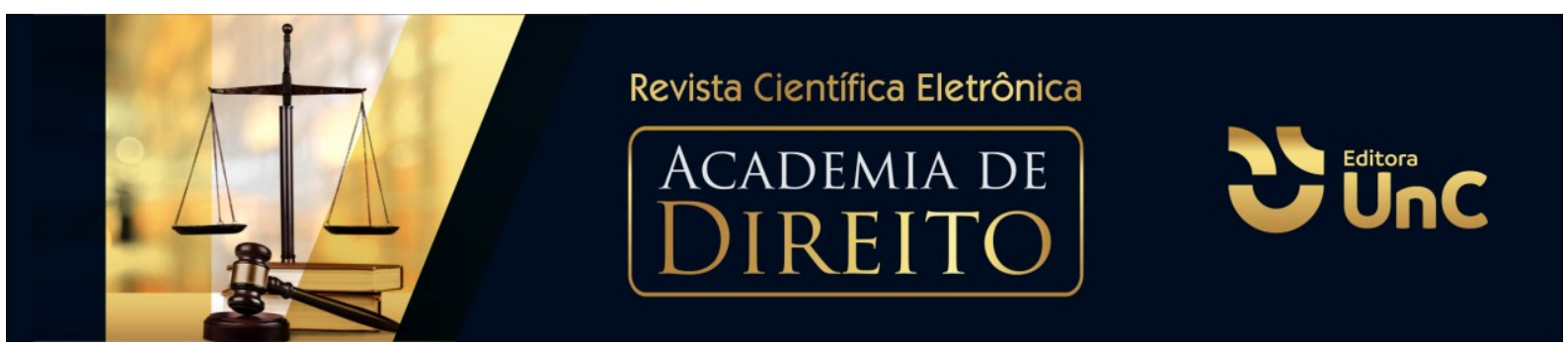

\title{
A CONDIÇÃO DOS REFUGIADOS E DE SEUS DIREITOS HUMANOS NO SÉCULO XXI NO BRASIL
}

\author{
Caroline Kuhl Machnicki ${ }^{1}$ \\ Patricia Minini Wechinewsky²
}

\begin{abstract}
RESUMO
O presente trabalho concentra-se nos Refugiados que deixam seus países de origem ou residência e buscam uma nova vida em outro. Como problema destaca-se o questionamento: como são garantidos os direitos humanos dos refugiados na atualidade (século XXI) no Brasil? Como hipótese aventa-se que apesar do Instituto do Refúgio ter se estagnado no final do século $X X$, atualmente com a evolução legislativa e políticas públicas o Brasil vem buscando meios de reforçar a proteção do direito humanitário aos refugiados. O objetivo geral consiste em analisar se os direitos humanos estão sendo garantidos aos refugiados que chegam ao Brasil neste século. Os objetivos específicos são apresentar brevemente a evolução histórica dos direitos humanos a nível mundial, a legislação brasileira em relação ao refúgio, bem como o órgão orientador e coordenador de proteção ao refugiado (CONARE) e elucidar o desenvolvimento dos direitos humanos e as medidas tomadas a partir do século XXI para a proteção e o amparo dos refugiados no Estado Brasileiro. Os conceitos a serem utilizados têm como marco teórico o direito internacional e nacional dos refugiados, a doutrina e legislação internacional e brasileira sobre o tema. A metodologia utilizada foi a revisão bibliográfica, utilizandose como delimitações: o espaço temporal do século XXI e o espaço geográfico dos refugiados que buscam se estabelecer no Brasil.
\end{abstract}

Palavras Chave: Refúgio. ACNUR. Migração. Estatuto dos Refugiados. Direitos Humanos.

\footnotetext{
${ }^{1}$ Graduanda em Direito pela Universidade do Contestado. Campus Mafra. Santa Catarina. Brasil. Email: caroline kuhl@hotmail.com

2Possui graduação em Direito pela Universidade do Vale do Itajaí (2002). Atualmente é professora na Universidade do Contestado (UnC). Campus Canoinhas e Mafra-SC. Tem pós-graduação latu sensu em Direito Privado Contemporâneo pela Universidade do Contestado, em Direito Processual Civil pela Uniderp e em Tradução de Inglês na universidade Estácio de Sá. Cursa Mestrado na Universidad de La Empresa - Uruguai no programa de pós-graduação strictu sensu em Direito das Relações Internacionais e Integração da América Latina. Universidade do Contestado Campus Mafra. Santa Catarina. Brasil. E-mail: patricia.mw@professor.unc.br. ORCID https://orcid.org/00000002-8381-5867.
} 


\title{
REFUGEE CONDITION AND THEIR HUMAN RIGHTS IN THE XXI CENTURY IN BRAZIL
}

\begin{abstract}
The present study aims the Refugees who leave their native or residency country searching for a new life elsewhere. As the problematic we underline the following question: how are the human rights of the refugees granted at the present time? The hypothesis we propose is that despite of the stagnation of the Institute of Refuge at the end of the $X X$ century, currently with legislation and public policy evolution, Brazil has been searching for means of strengthen the protection of the humanitarian rights to the refugees. The general objective consists of the analysis about how the human rights are granted to the refugees that come to Brazil in this century. The specific objectives are: to briefly present the historic evolution of the human rights, the Brazilian legislation regarding the refugees as well as the regulator and coordinator office for the refugees (CONARE) and to enlighten the development of the human rights and the measures taken in the $\mathrm{XXI}$ century regarding the protection and support to the refugees in Brazil. The concepts used have as theoretical framework the national and international law about refugees and national and international legal theory. The methodology was bibliographical review using as delimitation: time window of XXI century and geographic window the refugees that wished to settle in Brazil.
\end{abstract}

Key Words: Refugee. ACNUR. Migration. Refugees Statute. Human Rights.

\section{INTRODUÇÃO}

Embora haja uma relação inclusa de afeição e acolhimento, descrita em diversos documentos, principalmente por meio de protocolos e convenções das Nações Unidas, a questão da aceitação dos refugiados esta longe de parecer resolvida.

Pontos que incluem a xenofobia e o racismo são apenas alguns dos exemplos que dificultam o tema. $O$ presente trabalho concentra-se nessas pessoas que são forçadas a deixarem seus países de origem e buscar refúgio em outro.

A pesquisa procura responder ao seguinte problema: como estão garantidos os direitos humanos na atualidade (século XXI) no Brasil?

Como hipótese aventa-se que apesar do Instituto do Refúgio ter se estagnado no final do século $\mathrm{XX}$, atualmente com a evolução legislativa e políticas públicas o Brasil vem buscando meios de reforçar a proteção do direito humanitário 
aos refugiados. O objetivo geral consiste em analisar se os direitos humanos estão sendo garantidos aos refugiados que chegam ao Brasil neste século. Os objetivos específicos são apresentar brevemente a evolução histórica dos direitos humanos a nível mundial, a legislação brasileira em relação ao refúgio, bem como o órgão orientador e coordenador de proteção ao refugiado (CONARE) e elucidar o desenvolvimento dos direitos humanos e as medidas tomadas a partir do século XXI para a proteção e o amparo dos refugiados no Estado Brasileiro. Os conceitos a serem utilizados têm como marco teórico o direito internacional e nacional dos refugiados, a doutrina e legislação internacional e brasileira sobre o tema. A metodologia utilizada foi a revisão bibliográfica, utilizando-se como delimitações: o espaço temporal do século XXI e o espaço geográfico dos refugiados que buscam se estabelecer no Brasil.

Em um primeiro momento aborda-se a evolução histórica mundial dos direitos humanos desde a antiguidade até os marcos modernos como a Independência Norte-Americana e a Revolução Francesa.

Posteriormente o texto trabalha efetivamente os direitos humanos dos refugiados, conceituando e expondo as particularidades do refúgio, diferenciando os refugiados de asilados e os simples migrantes.

Em continuação, trata-se dos refugiados e sua proteção no Estado Brasileiro, em especial com o Estatuto dos Refugiados de 1997 e a Lei de Migração promulgada já no século XXI. Corroborando com a proteção aos direitos humanos dos refugiados apresentam-se dados oficiais em relação aos refugiados e informações sobre as políticas públicas promovidas pelo Brasil para a garantia dos direitos humanos dos refugiados.

\section{DIREITOS HUMANOS}

\subsection{HISTÓRICO}

O Direito humano, que abrange liberdade de se expressar, de viver, de trabalhar, entre outros é determinado como sendo um direito igualitário a todos e que independem de fatores ou condições, como raciais, étnicos, religiosos ou qualquer outro (ONU, 2016). 
$\mathrm{Na}$ antiguidade (3.500 a.C. a 476 d.C.), admitia-se a escravidão, a pena de morte, a tortura, entre outros tratamentos que são considerados extremamente cruéis na atualidade. Nessa época ainda não se falava de direitos humanos. O direito tinha apenas como propósito a tutela da vida, a integridade física, a honra, a família e a propriedade privada (SOBREIRA, 2013, p. 176).

$\mathrm{Na}$ fase denominada como pré-Estado Constitucional, ainda considerada antiguidade, não havia um regramento referente aos direitos humanos. Entretanto surgiram alguns costumes que poderiam ser considerados como tais, alguns valores, como por exemplo, a justiça e a igualdade, o que foi considerado um primeiro rumo à afirmação dos direitos humanos (RAMOS, 2018, p. 37).

Então foi no período axial, entre 600 e 480 a.C., que enfim se estabeleceram os princípios e valores fundamentais da vida. Neste momento, todos os seres humanos adquirem o direito de serem respeitados de forma igualitária, direitos que são reconhecidos até hoje (COMPARATO, 2017, p. 21).

Posteriormente, na Idade Média (entre meados de 476 a 1453 d.C.), os direitos humanos começaram a surgir, não com a mesma intensidade $e$ denominação que é atualmente, porém, com os mesmos objetivos. Somente no século XVII foi que os direitos humanos apontaram com os mesmos ideais e conteúdos da atualidade (SOBREIRA, 2013, p. 176).

Ainda, na Idade Moderna (1453 a 1789), é importante destacar que surgiram alterações nas dimensões sociais, econômicas e culturais. Nessa época, nasceram discussões sobre o conceito de autoridade, bem como sobre o constitucionalismo (SOBREIRA, 2013, p. 177-178).

Por fim, na Idade Contemporânea, discorrendo do ano de 1789 em diante o homem passou a ser reconhecido como "preocupação central" e o Estado como "federação soberana", coordenadora da vida social. Neste momento da humanidade, houve a ampliação da liberdade religiosa, assim como o início dos direitos do trabalhador: fixação de salário mínimo, descanso semanal remunerado, direito à greve, entre outros (SOBREIRA, 2013, p. 178).

O marco histórico da proteção dos diretos humanos foi "da Idade Antiga até a primeira metade do século $\mathrm{XX}$, quando ocorre a internacionalização da proteção dos direitos humanos" (OLIVEIRA, 2016, p. 31). 
Em 1776 a Declaração de Independência Norte-Americana traz em seu bojo proteções inéditas para o indivíduo contendo princípios democráticos apresentando o povo como "detentor do poder político supremo". A Revolução Francesa também mostrou ao mundo a luta por garantir a força e necessidade humana, isto é, "força" porque com a movimentação da população mudanças aconteceram e "necessidade" porque a pessoa humana contava com quase nenhum direito básico para a vida. $\mathrm{A}$ demonstração de força do povo resultou na Declaração dos Direitos do Homem e do Cidadão em 1795 - momento histórico para os direitos humanos (GUERRA, 2014, p. 10/11).

A partir da Declaração de Independência Norte-Americana e da Revolução Francesa, Guerra, 2014, leciona "[...] das declarações formais de direitos, passou-se à sua incorporação nos textos constitucionais, inicialmente como preâmbulo, e, às vezes, como capítulo autônomo" (GUERRA, 2014, p. 11).

A Declaração Universal dos Direitos Humanos, consagrada pela Assembleia Geral da ONU, assinalou uma nova direção do humanitário contemporâneo. A Declaração configurou-se como a primeira resposta jurídica da comunidade internacional que assegura o direito de todo ser humano ter hospitalidade universal; o direito de ter direitos (LAFER, 1999, p.174-175).

Esta Declaração teve sua primeira etapa concluída em 18 de junho de 1948. A segunda etapa trouxe decisões referentes aos direitos civis, políticos, econômicos, sociais e culturais, e foi concluída no ano de 1966. E, por fim, a terceira etapa está baseada na criação de mecanismos que tem a finalidade de assegurar a universal observância dos direitos, contudo, ainda não foi completada (COMPARATO, 2017, p. 237-238).

\footnotetext{
Para sistematizar o estudo das fases anteriores rumo à consagração dos direitos humanos, usamos a própria Declaração Universal de 1948, para esclarecer os seguintes parâmetros de análise das contribuições do passado à atual teoria geral dos direitos humanos: 1) o indicativo do respeito à dignidade humana e igualdade entre os seres humanos; 2) o reconhecimento de direitos fundado na própria existência humana; 3) o reconhecimento da superioridade normativa mesmo em face do Poder do Estado e, finalmente 4) o reconhecimento de direitos voltados ao mínimo existencial (RAMOS, 2018, p. 34).
}

Desta forma, os direitos humanos passaram a ser protegidos no âmbito internacional. Mazzuoli, 2018, destaca que quando se tratar de proteção dos direitos 
humanos não importa a nacionalidade da pessoa, e, afirma que os direitos fundamentais na ordem interna (no que se refere à Constituição de cada respectivo Estado) começaram a ser aplicados a nível internacional. Isso decorreu principalmente da vontade do sistema internacional de proteger os direitos das pessoas em face de abusos cometidos por autoridades estatais. Eis que, a título de ilustração, segue seu diagrama (MAZZUOLI, 2018, p. 23):

Figura 1 - Organograma

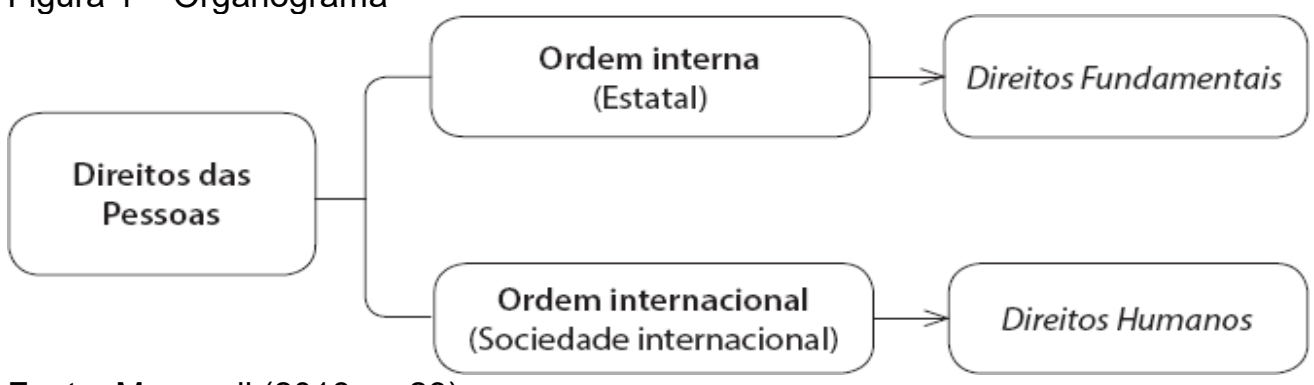

Fonte: Mazzuoli (2018, p. 23)

Observa-se pelo exposto que os Direitos Humanos são reconhecidos internacionalmente e os Direitos Fundamentais são reconhecidos no Estado, como ordem interna de cada constituição vigente (MAZZUOLI, 2018, p. 23).

\begin{abstract}
Foi durante o período axial da História, que se despontou a ideia de uma igualdade essencial entre todos os homens. Mas foram necessários vinte e cinco séculos para que a primeira organização internacional a englobar a quase totalidade dos povos da Terra proclamasse, na abertura de uma Declaração Universal de Direitos Humanos, que 'todos os homens nascem livres e iguais em dignidade e direitos' (COMPARATO, 2017, p. 24).
\end{abstract}

Para tanto, tem-se que os direitos essenciais dos seres humanos são basicamente os "direitos humanos, direitos fundamentais, direitos naturais, liberdades públicas, direitos do homem, direitos individuais, direitos públicos subjetivos e liberdades fundamentais" (RAMOS, 2018, p. 51).

O direito à vida, à liberdade de opinião e de expressão, além do direito ao trabalho e à educação, são alguns dos quais são englobados pelos direitos humanos universais. Foram estabelecidas obrigações aos governos, a partir do Direito Internacional dos Direitos Humanos, para que estes possam agir ou se abster de certos atos, desde que promovam e protejam tais direitos destinados à grupos ou indivíduos (ONU, 2016). 
Por fim, a partir de um embasamento do contexto histórico dos direitos humanos, é importante observar que já havia indícios na antiguidade de preocupação na observância dos direitos e deveres. Com o passar dos anos, conforme necessidades e fatos históricos categóricos, os direitos e deveres evoluíram, criando também meios de fortalecimento quanto à proteção do humanitário.

\subsection{EVOLUÇÃO DOS DIREITOS HUMANOS DOS REFUGIADOS}

A palavra refúgio deriva do vocábulo latino refugium, que é definido como "esconderijo, lugar para esconder-se, abrigo, amparo", enquanto o termo "refugiado" refere-se ao "abrigado, fugido, escondido" (SCOTTINI, 2009, p. 463).

Na Grécia Antiga o termo asilo já se fazia presente, porém, com o passar dos anos e acontecimentos, é frisado que ocorre a evolução deste segmento para uma instituição do Direito consuetudinário, formando garantias ao ser humano que necessitar de proteção fora de seu ambiente de origem (ALMEIDA, 2015, p. 90).

As definições e principais diferenças entre os asilados e exilados são aspectos importantes. Exilado é aquele que vive distante de sua terra natal e a deixou voluntária ou forçosamente. Quando se tratar de vontade própria será considerado um exilado migrante, e, caso se tratar de forma forçosa será considerado um exilado stricto sensu. Ademais, no que se refere ao asilado, há o reconhecimento jurídico da existência de uma perseguição (ALMEIDA, 2015, p. 84 85).

Quando uma pessoa está sendo perseguida, não chega a perder sua nacionalidade; todavia, por circunstâncias alheias a sua própria vontade, não pode exercitar sua cidadania de modo regular, tendo dificuldades de exercer direitos básicos, como o de ir e vir e o de moradia. É obrigada, em algumas situações, a viver na clandestinidade (ALMEIDA, 2015, p. 85).

Já os migrantes são considerados os que desejam sair de seus países de origem em busca de um objetivo, como melhora de vida, buscando educação ou trabalho, sem sofrer qualquer tipo de ameaça ou perseguição. Deste modo os migrantes são tratados pelos países de acordo com a legislação de seu país de 
origem, já os refugiados são tratados através de normas de refúgio e de proteção reconhecidos mundialmente (ACNUR, 2015).

Segundo a Organização das Nações Unidas (2016) as pessoas que estão fora de seus países de origem e que não podem ou não desejam o retorno, seja pelos mais diferentes motivos: perseguição, conflitos, violência ou outras circunstâncias que perturbam a ordem pública e que, a partir daí, necessitam de proteção internacional, são conceituados como refugiados.

Entretanto, é necessário buscar a historicidade dos momentos que hoje de fato amparam e referenciam o refúgio. Antes da criação da ONU - Organização das Nações Unidas - a perspectiva social era de proteger as pessoas independente de qualquer definição de grupo, mas que estes tivessem sido afetados por algum evento social ou político. Refugiados eram vistos como membros de grupos de pessoas privadas de proteção de seus Estados de origem (CARNEIRO, 2012, p. 14).

De acordo com o Alto Comissariado das Nações Unidas para os Refugiados ACNUR, foi a criação em 1921 de um programa liderado por Fridjof Nansen para a proteção de milhares de russos que deixaram seu país após a queda do Império Otomano e da Revolução Russa, que marcou o real esforço praticado pela comunidade internacional para tornar o termo "refugiados" um importante assunto em âmbito mundial, buscando assumir responsabilidades de assistência e proteção para com estas pessoas (ACNUR, 2018).

A chamada "Carta de São Francisco" é vista como fator chave para dissimular o conceito de que a guerra seria uma forma lícita e jurídica para impor o Direito, transformando assim em um instrumento ilegal para a decisão de conflitos (ALMEIDA, 2015, p. 39).

A Carta foi elaborada por representantes de diversos países na Conferência sobre Organização Internacional em São Francisco, no ano de 1945, e consagrou-se como um marco para a instauração da proteção do ser humano, criando a Organização das Nações Unidas (ONU, 2018).

A partir da década de 50 foram diversos os tratados e pactos que buscavam aperfeiçoar acordos e direitos, singularizando grupos (ONU, 2018). Tais tratados como em 1951 na Convenção relativa ao Estatuto do Refugiado, o protocolo de 1967 e a Declaração de Cartagena de 1984 (que reforçaram o Estatuto), o Direito 
Internacional dos Refugiados tornou-se um dos ramos do Direito Internacional dos Direitos Humanos (ALMEIDA, 2015, p.80-81).

Em dezembro de 1950 foi criado o ACNUR - Alto Comissariado das Nações Unidas para Refugiados - por resolução da Assembleia Geral das Nações Unidas, objetivando efetivar, a nível universal, a proteção dos refugiados. Iniciou suas atividades em janeiro de 1951, com um mandato inicial de três anos para reassentar refugiados europeus que estavam sem lar após a Segunda Guerra Mundial. De acordo com o seu estatuto, suas funções primordiais são providenciar proteção internacional e buscar soluções permanentes para o problema dos refugiados, tendo como base a Convenção de 1951 da ONU.

\begin{abstract}
Sentia-se a necessidade de um novo instrumento internacional que definisse a condição jurídica dos refugiados. Ao invés de formular acordos ad hoc para situações específicas de refugiados, optou-se por um instrumento único contendo a definição geral das pessoas que deveriam ser consideradas como refugiados. A Convenção relativa ao Estatuto dos Refugiados foi adotada por uma Conferência de Plenipotenciários das Nações Unidas, em 28 de julho de 1951, e entrou em vigor a 21 de abril de 1954. Nos parágrafos seguintes, esta Convenção é denominada 'Convenção de 1951' (ACNUR, 2011, p. 5).
\end{abstract}

Em Genebra, na data de 28 de julho de 1951 a Convenção relativa ao Estatuto dos Refugiados foi concluída e, por conseguinte, amparada pela Conferência das Nações Unidas de Plenipotenciários (RAMOS, 2018, p. 180).

A Conferência, porém, partia de linhas de pensamento distintas: uma entendia que a Convenção devia ser tratada de forma ampla e abrangendo todos os refugiados; a outra buscava restringir sua aplicação aos refugiados europeus (ACNUR, 2013).

Após sua assinatura, a citada convenção é considerada como eixo fundador do Direito Internacional dos Refugiados, já que define o refugiado em um de seus capítulos, além de estabelecer um padrão de tratamento para os que são abrigados com essa definição (ACNUR, 2005).

O que indica a principal singularidade e característica da Convenção é que esta individualiza o refugiado, centrando na pessoa humana perseguida e sem proteção. O refugiado neste contexto é um ser de crenças, pertencente à grupos sociais, que possui uma nacionalidade, uma raça declarada e por estes fatores e por 
seus ideais políticos próprios é perseguido e não tem amparo e proteção de seu Estado de origem, ou este não pode protegê-lo (CARNEIRO, 2012, p. 17).

É concedida ao refugiado a garantia dos direitos civis básicos, que incluem liberdade de pensamento e de deslocamento, além dos direitos fundamentais inerentes a todos os indivíduos. Todos devem ter assistência médica, adultos devem ter direitos ao trabalho e crianças à escolaridade (ACNUR, 2018).

No Brasil, a Convenção de 1951 foi aprovada pelo Congresso Nacional, no Decreto Legislativo n. 11, de 17 de julho de 1960 (RAMOS, 2018, p. 180-181).

\begin{abstract}
A proteção da Convenção poderá cessar em hipóteses nela expressamente discriminadas, relacionadas ao fato de que a pessoa recuperou a nacionalidade voluntariamente ou voltou a se valer da proteção do país de que é nacional; adquiriu nova nacionalidade e, consequentemente, a proteção do país cuja nacionalidade adquiriu; voltou a estabelecer-se, voluntariamente, no país que abandonou; se deixaram de existir as circunstâncias em consequência das quais a pessoa foi reconhecida como refugiada (RAMOS, 2018, p. 181-182).
\end{abstract}

Ocorre que a convenção de 1951 limitou temporal e geograficamente a condição de refugiado. O protocolo de 1967 refuta a limitação temporal explícita na Convenção de 1951, onde era descrito no texto sobre acontecimentos ocorridos antes de $1^{\circ}$ de janeiro de 1951 e, também, a limitação geográfica, já que englobava eventos Europeus. O novo documento eliminou tais limitações, firmando a proteção dos direitos aos que se tornaram refugiados a partir de todos os outros eventos em âmbito mundial e sem especificar um ponto de partida (RAMOS, 2018, p. 181).

Embora haja uma ligação entre o Protocolo de 1967 e a Convenção de 1951, o primeiro pode ser considerado como um instrumento jurídico próprio do Direito Internacional e tem um caráter individual, podendo ser aderido de forma singular sem que os dispositivos da Convenção se tornem inaplicáveis ou nulos quanto à aplicação dos Estados. Entretanto, houve o interesse por parte de vários países de adotar os dois instrumentos, com o objetivo de reforçar a autoridade de ambos quanto à proteção dos refugiados em nível universal (ARAUJO; BARRICHELLO, 2014, p. 74).

Os motivos do refúgio, trazidos pelo Estatuto de 1951 e pelo Protocolo de 1967, foram bem abrangentes, pois, ao estabelecerem os motivos básicos já que podem ser ampliados pelas leis internas de cada país e por diplomas regionais -, tais documentos visam garantir segurança jurídica na 
concessão do status de refugiado nos Estados-partes e evitar decisões dissonantes entre os órgãos competentes pela acolhida do migrante em deslocamento forçado (GUERRA, 2017, p. 36).

A questão dos refugiados está estritamente ligada a duas dimensões: humanitária e política. Explicam trazendo a importância da proteção à vida e aos direitos dos seres humanos, mas também dependem de diferentes tipos de interesse por parte de Estados ou instituições. Embora haja decisões que amparam os refugiados, como a Declaração Universal de 1948 e a Convenção de 1951, a concessão do asilo é um ato soberano do Estado que tem o dever de controlar seu território e fronteiras (REIS; MOREIRA, 2010, p. 18).

Toda e qualquer pessoa ou grupo que tente o asilo ou migração passou a ser visto como uma ameaça em potencial às sociedades que os recebem. Isto, mas não somente, pela conservação da identidade de determinada nação. Desta forma, hoje há uma ideia de controle, para a prevenção e contenção desses "invasores" em diversos países do globo (GOODWIN-GILL, 2001, p. 15).

Da mesma forma, os fluxos de larga escala originados por conflitos em países em desenvolvimento (sobretudo da África) fizeram com que os países vizinhos e da região posicionassem-se contra a recepção de refugiados, tendo em vista os custos financeiros e políticos envolvidos nessa decisão. Em casos de grandes contingentes de refugiados, por motivos de violência generalizada, conflitos internos e violação maciça de direitos humanos, dentre outros, os indivíduos são reconhecidos coletivamente como refugiados, a partir do critério prima facie - o que coloca em xeque a capacidade de absorção dos Estados receptores (REIS; MOREIRA, 2010, p. 22).

No entanto, com o aprofundamento da Guerra Fria e a deflagração de processos de independência, além de conflitos africanos e na América Central, ficou claro que o problema dos refugiados não só não estava resolvido como de fato aumentava. Em 1984 houve, portanto, em Cartagena, uma nova reunião entre Estados para um novo debate sobre o assunto que não apenas estendeu o conceito de refugiado, mas partiu de bases completamente distintas para definir o estatuto do refugiado (CARNEIRO, 2012, p. 16-17).

Para Cartagena devem ser considerados refugiados:

[...] as pessoas que tenham fugido dos seus países porque a sua vida, segurança ou liberdade tenham sido ameaçadas pela violência 
generalizada, a agressão estrangeira, os conflitos internos, a violação maciça dos direitos humanos ou outras circunstâncias que tenham perturbado gravemente a ordem pública (DECLARAÇÃO DE CARTAGENA, 1984, p.3).

O conceito, portanto, se constrói a partir dos direitos fundamentais da pessoa humana, a partir da proteção da vida, segurança e liberdade. Nesse passo, é complementado justamente pela realidade objetiva que ameaça tais direitos, com o fundado temor que afeta a pessoa do refugiado (CARNEIRO, 2012, p. 19).

A questão dos refugiados é hoje um problema de todas as comunidades, e que merece mais respeito quanto aos bens e valores em quaisquer circunstâncias. É necessário que haja consciência ética e coletiva, avançando para além de normas jurídicas e se comece a considerar os regimes internacionais como um todo, abrangendo costumes, princípios, acordos, para que de fato encontrem-se soluções para os deslocamentos forçados ao redor do globo (SILVA; RODRIGUES, 2012, p. 141).

\section{ESTADO BRASILEIRO - DO ESTATUTO DOS REFUGIADOS DE 1997}

Os principais pilares relativos à proteção dos refugiados se mantêm ligados à Convenção das Nações Unidas sobre o Estatuto do Refugiado de 1951 e seu Protocolo de 1967. Além destes, diversos outros documentos regionais ao redor do planeta reforçaram a garantia dos direitos humanos e das suas liberdades fundamentais (MARQUEZ, 2017, p.13).

No Brasil, foi criada no ano de 1997 a Lei n. 9.474 a qual se tonou um exemplo a ser seguido de forma regional e um marco na história da proteção aos refugiados, além de demonstrar e firmar o compromisso humanitário brasileiro em âmbito internacional (JUBILUT; GODOY, 2017, p. 9).

Diferentemente do que a normativa interna dos países latino-americanos que, em sua maioria, se limitava a citar o órgão encarregado da proteção e a indicar os procedimentos para ser condicionado como refugiado, a nova legislação do Brasil interpôs um cenário amplo, indicando políticas públicas integradas, além de buscar soluções que de fato fossem duradouras aos refugiados (GONZÁLEZ, 2010, p. 52). 
A normativa amplia ainda, assim como a Declaração de Cartagena de 1984, a definição de refugiado anteriormente vigente, abrangendo um número maior de pessoas que necessitam de proteção internacional. Estas, que apesar de não sofrerem perseguições e ameaças individuais, são vítimas de grave violação dos direitos humanos (MARQUEZ, 2017, p. 14).

O Estado brasileiro utiliza da mutação ocasionada ao longo dos anos do princípio de soberania estatal para se fazer exemplo em meio ao estatuto do refúgio em âmbito internacional. O Brasil, ao fazer o uso de sua soberania, protege os direitos humanos de estrangeiros que não obtiveram apoio em seu país de origem; país que falhou em lhes oferecer tal proteção (CARNEIRO, 2017, p. 103).

Embora haja uma constante mudança no conceito de soberania Estatal, não há como negar sua autonomia quanto às decisões tomadas dentro de seus limites territoriais em relação aos não nacionais, categoria que se encontram os refugiados. Mesmo com a existência de diversas normativas do Direito Internacional; Direito Internacional dos Direitos Humanos; Direito Internacional dos Refugiados e do Direito Humanitário, o Estado é autônomo na aceitação ou não desses indivíduos em seu domínio territorial (UBER, 2012, p. 107).

Ademais, com a vigência da nova lei, a temática do refúgio em território brasileiro passa a ser um dos aparatos mais modernos do mundo. Incorporando o que há de mais contemporâneo na discussão, a legislação determina providências para a criação do Comitê Nacional para os Refugiados (CONARE), um órgão orientador e coordenador de ações de proteção, assistência e apoio jurídico aos necessitados (LEÃO, 2005, p. 4).

Sobre o CONARE explica González, 2010:

[...] no caso do Brasil, a determinação da condição de refugiado é realizada por um órgão colegiado, o CONARE, composto por representantes de distintos ministérios (Justiça, Relações Exteriores, Trabalho, Saúde e Educação), além de um representante do Departamento da Polícia Federal e de organização não-governamental que se dedique a atividades de assistência e proteção de refugiados no país (GONZÁLEZ, 2010, p. 55).

O ACNUR se faz tranquilizado após a posição brasileira na criação da lei em 1997, visto que seu objetivo era a construção e o fortalecimento de uma estrutura tríplice, que era formada pelo Governo, sociedade civil e ACNUR. Após a efetivação 
deste sistema, o ACNUR veio a montar seu escritório no Brasil para manter e auxiliar mais prontamente os assuntos do refúgio no país (LEÃO, 2005, p. 2).

Algumas das boas práticas que estão incluídas na normativa destacam-se:

1. A proteção internacional dos refugiados se assume como uma política de Estado:

2. Incorporação de uma definição de refugiado mais ampla;

3. Estabelecimento de um órgão colegiado para a determinação da condição de refugiado;

4. Participação de representantes da sociedade civil dentro do órgão nacional para a determinação da condição de refugiado;

5. Regulação dos direitos e obrigações dos refugiados, incluindo o direito ao trabalho para os solicitantes de refúgio;

6. Assistência administrativa para os refugiados;

7. Busca de soluções duradouras e a participação do Brasil como país emergente de reassentamento (GONZÁLEZ, 2010, p. 52).

De acordo com a Lei n. 9.474 de 22 de julho de 1997, o processo de solicitação de refúgio, assim que chega ao Brasil, primeiramente necessita do registro junto à autoridade migratória do Departamento de Polícia Federal nos aeroportos, portos ou na fronteira terrestre por onde o refugiado entra no país.

Após, o Comitê Nacional para Refugiados, responsável por conceder o pedido, decide em primeira instância sobre a solicitação. Concedido o pedido de refúgio, o estrangeiro poderá trabalhar no país. O pedido de refúgio é estendido ao cônjuge, pais e filhos dos estrangeiros e aos membros que dependerem dele economicamente, desde que se encontrem no território nacional. Não podem pedir refúgio os indivíduos que já possuem proteção ou assistência por parte de algum organismo ou instituição das Nações Unidas que não seja o próprio ACNUR.

A esse respeito, a Lei esclarece que não poderão solicitar refúgio os estrangeiros que tenham cometido crimes contra a paz, de guerra, contra a humanidade, crime hediondo, e participado de atos terroristas ou tráfico de drogas.

Ainda de acordo com o Estatuto brasileiro, os refugiados poderão solicitar concessão de permanência definitiva no Brasil. O processo é feito via Ministério da Justiça e o pedido deve ser feito de acordo com algumas condições, como: o indivíduo deve residir no País por pelo menos seis anos como refugiado, ser profissional contratado por instituição instalada no Brasil, ser profissional de capacitação reconhecida por órgão da respectiva área de atuação e, por fim, estar estabelecido com negócio e capital próprio. 
Todos devem cumprir a Lei e seguir as regras do país de onde vivem, como estabelece o art. 21 da Convenção das Nações Unidas:

No que concerne ao alojamento, os Estados Contratantes darão, na medida em que esta questão seja regulada por leis ou regulamentos ou seja submetida ao controle das autoridades públicas, aos refugiados que residam regularmente no seu território, tratamento tão favorável quanto possível e, em todo caso, tratamento não menos favorável do que o que é dado, nas mesmas circunstâncias, aos estrangeiros em geral (ONU, 1951, p. 11).

De acordo com o Ministério das Relações Exteriores, todos os pedidos de refúgio são decididos pelo CONARE, o requisito inicial para poder realizar tal solicitação é estar presente no território nacional. O estrangeiro que estiver sofrendo algum tipo de perseguição deverá procurar uma delegacia de Polícia Federal, ou então, autoridade migratória na fronteira, a fim de solicitar o refúgio com amparo e proteção do governo brasileiro.

À vista disso, o Ministério da Justiça ressalta ainda que os solicitantes necessitam renovar o protocolo encaminhado na Polícia Federal a cada 180 dias, estando sujeitos ao arquivamento do pedido de refúgio, caso não renovado. O CONARE julga de extrema importância todos os documentos que expliquem os motivos pelos quais o estrangeiro saiu do seu país. O estrangeiro que solicitar o refúgio e faltar sem justificativa na entrevista ficará submetido ao arquivamento da solicitação (CONARE, 2019).

Os dados do Ministério da Justiça (2018) representados no Quadro 1 demonstram o tempo discorrido entre a solicitação de reconhecimento como refugiado e a decisão imposta por parte do governo federal brasileiro.

Quadro 1 - Solicitações de refúgio e ano de resposta.

\begin{tabular}{|c|c|c|c|}
\hline ANO DE SOLICITAÇÃO & PAÍS DE ORIGEM & ANO DA DECISÃO & STATUS \\
\hline 2012 & QUÊNIA & 2019 & INDEFERIDO \\
\hline 2014 & GUIANA & 2019 & INDEFERIDO \\
\hline 2014 & PAQUISTÃO & 2019 & DEFERIDO \\
\hline 2015 & QUÊNIA & 2019 & DEFERIDO \\
\hline 2015 & TOGO & 2019 & INDEFERIDO \\
\hline 2016 & SÍRIA & 2019 & DEFERIDO \\
\hline 2016 & ANGOLA & 2019 & INDEFERIDO \\
\hline 2016 & VENEZUELA & 2019 & $\begin{array}{c}\text { EXTINÇÃO (DESISTÊNCIA } \\
\text { SEM FORMULÁRIO) }\end{array}$ \\
\hline 2017 & EQUADOR & 2019 & $\begin{array}{c}\text { EXTINÇÃO (DESISTÊNCIA } \\
\text { SEM FORMULÁRIO) }\end{array}$ \\
\hline
\end{tabular}




\begin{tabular}{|c|c|c|c|}
\hline 2017 & SENEGAL & 2019 & INDEFERIDO \\
\hline 2018 & BANGLADESH & 2019 & INDEFERIDO \\
\hline 2018 & VENEZUELA & 2019 & DEFERIDO \\
\hline
\end{tabular}

Observa-se na tabela com decisões sobre pedidos de reconhecimento da condição de refugiado - ACNUR (1993-1997) e CONARE (1998 a janeiro de 2019) que anteriormente o lapso temporal para decisão da aprovação ou não dos refugiados no Brasil estava sendo maior que atualmente, como por exemplo, o indivíduo que solicitou refúgio no ano e de 2012 e foi aprovado somente em 2019 (BRASIL. MINISTÉRIO DA JUSTIÇA, 2018).

Pela análise dos dados expostos, há uma mostra da preocupação do Estado brasileiro em relação à resposta ao indivíduo que necessita de apoio. Quando há uma manutenção na agilidade de processamento dos pedidos, é demonstrado o interesse do Brasil em garantir o humanitário, diminuindo a expectativa de mudança de status de cada refugiado que busca entrar no país e protegendo os direitos humanos.

Por outro lado, atualmente há casos em 2018 que já foram aprovados em seguida no início de 2019. O CONARE possui uma resolução específica para as pessoas que acabaram tendo a solicitação extinta, esta dispõe "sobre a extinção do processo e regras de desarquivamento do processo de refúgio" - Resolução n. 28 de 20 de dezembro de 2018.

No ano de 2017 , os pedidos chegaram a 33.866 solicitações. Com o passar dos anos os pedidos aumentam cada vez mais, como se observa segundo os dados do Ministério Justiça (BRASIL. MINISTÉRIO DA JUSTIÇA, 2018, p. 9).

O número de solicitações de refúgio triplicou no Brasil no ano de 2017 , comparado com o ano de 2016. Até o referido período, nunca houve tantas solicitações de refúgio enviadas ao CONARE, fugindo principalmente da pobreza, das guerras, de perseguições políticas, entre outros (BRASIL. MINISTÉRIO DA JUSTIÇA, 2018).

O grande fator pode estar relacionado ao crescente número de conflitos no âmbito da América do Sul, tais como, Venezuela e Argentina, os quais fazem fronteira territorial do Brasil, o que acaba facilitando a migração dos povos. 
Refugiado, o CONARE informou que o Brasil acolhe 4.336 refugiados de 76 diferentes nacionalidades, sendo de maior incidência os provenientes de Angola, Colômbia, República Democrática do Congo, Iraque, Libéria e Síria. Em S. Paulo (SP), a Caritas Arquidiocesana registrou que, entre janeiro e novembro de 2013 , atendeu mais de 2,7 mil novos solicitantes de refúgio, de mais de 60 nacionalidades, com destaque por Bangladesh, Nigéria, Senegal e Congo, além da Síria (JUBILUT; GODOY, 2017, p. 39).

Em análise dos dados mais recentes, o Ministério da Justiça traz que o CONARE decidiu 13.084 processos de solicitantes de refúgio de 84 nacionalidades em 2018, tendo sido reconhecida a elegibilidade de 777 casos de pedido de refúgio e estendido essa condição a 309 casos, conforme demonstra gráfico abaixo (BRASIL. MINISTÉRIO DA JUSTIÇA, 2019):

\section{Gráfico 1 - Decisões do CONARE em 2018}
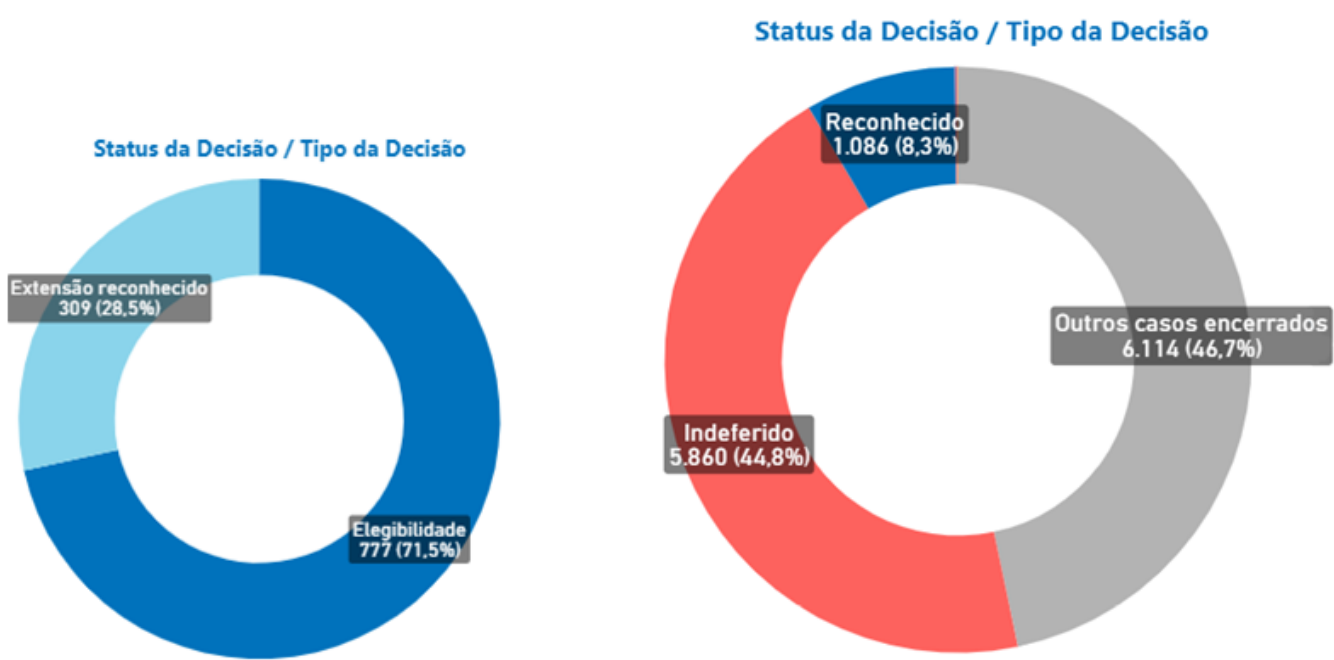

Fonte: Brasil. Ministério da Justiça (2019)

Após 22 anos, a referida Lei Brasileira de Refúgio continua sendo um exemplo legal no que se refere ao amparo de pessoas refugiadas. "O atual desafio que se impõe ao Brasil é garantir que o sistema brasileiro de refúgio possa ser aperfeiçoado, especialmente em relação ao processo de integração local de pessoas refugiadas" (MARQUEZ, 2017, p. 14).

A proteção dos que necessitam de auxílio quanto às perseguições sofridas em seus Estados-origem, as quais tiveram seus direitos fundamentais violados por sua raça, nacionalidade, crença religiosa, opiniões políticas e sua posição quanto à grupos sociais específicos, iniciam, principalmente, a partir do estudo profundo e conhecimento do texto da lei brasileira. Há uma necessidade quanto à compreensão 
desse aparato jurídico para que se dê um passo importante na proteção dos refugiados em âmbito nacional, já que apenas a redação do texto não é suficiente nesse aspecto (JUBILUT; GODOY, 2017, p. 10-11).

Ao demonstrar sua preocupação com a resposta dos pedidos encaminhados ao CONARE pelos que necessitam do refúgio, o Brasil corrobora seu compromisso com a garantia dos direitos humanos. O Estado brasileiro busca responder as solicitações o mais rápido possível, já que entende que, mesmo com a resposta do pedido sendo indeferida, o indivíduo necessitado tem seu tempo de expectativa reduzido.

\section{DAS POLÍTICAS PÚBLICAS PROMOVIDAS PELO BRASIL PARA A GARANTIA DOS DIREITOS HUMANOS DOS REFUGIADOS}

Políticas públicas podem ser definidas como "a totalidade de ações, metas e planos que os governos (nacionais, estaduais ou municipais) traçam para alcançar o bem-estar da sociedade e o interesse público" (LOPES; AMARAL; CALDAS, 2008, p. 5).

Tendo em vista que atendem às demandas da sociedade, as políticas públicas ficarão a cargo de um formulador responsável, o qual irá fazer uma seleção das demandas prioritárias para cada ente, e, posteriormente vai encaminhar as respostas, as quais nem sempre serão positivas para todos. Portanto, a atuação do interesse público visa sempre o bem-estar social. Dito de outro modo, políticas públicas podem ser descritas em dois principais pontos: gerais e específicos, os quais são resultado de lutas entre grupos e segmentos da população, que vão em busca de melhorias próprias ou que afetam um todo (LOPES; AMARAL; CALDAS, 2008, p.7).

Considerando que no Brasil mais de 9.552 pessoas já foram reconhecidas na condição de refugiadas, adveio um grande desafio, porém um fortalecimento do sistema de refúgio no país. Como é necessário aumentar a estrutura administrativa, estão sendo realizados investimentos em pessoal e em capacitação. Dessa forma, houve um desenvolvimento na tramitação dos processos relacionados ao refúgio, com a finalidade de estabelecer agilidade no andamento processual (BRASIL. MINISTÉRIO DA JUSTIÇA, 2017). 
A Declaração e Plano de Ação do Brasil, realizada no ano de 2014, é um marco de cooperação e solidariedade Regional para fortalecer a proteção internacional das pessoas refugiadas.

É de grande importância observar que a Declaração do Brasil tem como um dos grandes objetivos algumas implementações de políticas públicas, as quais promovem a integração local dos refugiados, juntamente com o auxílio do Estado, do ACNUR e da sociedade civil. Destaca-se, ainda, o amparo das autoridades locais, do setor privado e das próprias comunidades que os acolhem (DECLARAÇÃO DO BRASIL, 2014, p. 3).

[...] a adoção de normativa interna que incorpora altos padrões de proteção do direito internacional dos refugiados e dos direitos humanos; o fortalecimento dos órgãos nacionais de determinação da condição de refugiado; a inclusão de um enfoque diferenciado em matéria de gênero, idade e diversidade; e maior envolvimento das autoridades de asilo na adoção de políticas públicas em matéria de refugiados (DECLARAÇÃO DO BRASIL, 2014, p. 9)

Ademais, é necessário ressaltar a preocupação da Declaração com os que detêm uma situação prolongada de refúgio em relação aos países que os acolhem. Estes são alguns dos objetivos da Declaração para se alcançar soluções duradouras relacionadas aos que se encontram na condição de refugiado (DECLARAÇÃO DO BRASIL, 2014, p. 11).

A Declaração interpõe ainda a continuidade quanto ao desenvolvimento de políticas públicas, objetivando avanços sociais e econômicos, além de proteger geograficamente os refugiados, além de, como cita a Declaração: "a execução de programas de atenção específica a populações retornadas, para criar as condições necessárias de repatriação voluntária em dignidade e segurança" (DECLARAÇÃO DO BRASIL, 2014, p. 12).

O Ministério da Justiça, como fortalecimento do Sistema Nacional de Refúgio, realizou uma Estruturação de políticas públicas recentes, dentre elas destaca-se a Lei de Migrações (n. 13.445/2017), bem como a Resolução Normativa n. 23 do CONARE, aprovada no ano de 2016 (BRASIL. MINISTÉRIO DA JUSTIÇA, 2017).

Cita-se alguns exemplos de decisões do órgão Executivo e Legislativo, que tem como base as Políticas Públicas, porquanto dão amparo ao refúgio no Brasil: a capacitação de servidores públicos para trabalhar com pessoas de grupos 
vulneráveis; políticas para tratar crianças com deficiência, bem como a situação das crianças refugiadas; orientar as mulheres que sofrerem algum tipo de violência para tomar adoção de providências pertinentes, entre outros destaques (BRASIL. MINISTÉRIO DA JUSTIÇA, 2017, p. 41).

Nesse passo, ainda, destaca-se alguns exemplos de políticas públicas adotadas também pelos órgãos Legislativo e Executivo, no que tange à regularização de documentos: a criação de um "visto universal", aplicável a todos e sem restrições; regularizar o exercício de atividade remunerada para estudantes; aperfeiçoamento e capacitação dos servidores que realizam a regularização documental das pessoas refugiadas; regularizar a possível mudança de visto, sem que precise sair do Brasil; entre outras relevâncias (BRASIL. MINISTÉRIO DA JUSTIÇA, 2017, p. 42).

Destaca-se também a criação, a partir do Estatuto Brasileiro do Refugiado de 1997, de vários conselhos e comitês ao longo do território. Estados como Rio Grande do Sul, Paraná, Minas Gerais, São Paulo e Goiás, entre outros, possuem tais meios governamentais em seus limites estatais que objetivam promover a integração da população que se encontra em situação de refúgio (ACNUR).

É notório que o Brasil está desenvolvendo e criando políticas públicas para cada vez mais amparar a proteção das pessoas refugiadas e, com isso, gerando a oportunidade dessas famílias, crianças, e mulheres continuarem suas vidas com acolhimento e acompanhamento para interação da cultura brasileira. Ademais, para que tenham um digno emprego, uma vida social nas escolas, com a devida fiscalização.

Desde o final do século XX, com a inserção do Estatuto dos Refugiados, o Estado brasileiro vem caminhando à passos largos e mostrando-se como exemplo mundial na resolução da pauta dos refugiados. Com órgãos públicos atuantes como - CONARE, normas legais direcionadas à novos desafios e através de políticas públicas cada vez mais modernas, sendo revistas de tempos em tempos, o Brasil se mostra grandioso na busca da garantia dos direitos humanos de pessoas que buscam a ressocialização e sua própria dignidade após serem obrigados a buscar uma nova vida. 


\section{CONCLUSÃO}

A partir das duas Grandes Guerras mundiais, com um grande processo migratório ao redor do globo, houve uma importante iniciação por parte da ONU e dos países quanto à preocupação individual com os que necessitavam vida nova $\mathrm{e}$ também com os países que os acolhiam.

No passar dos anos, com a criação do Estatuto dos Refugiados de 1951, fortalecido pelo Protocolo de 1967 e após, com a Declaração de Cartagena, foi notório a evolução do assunto e da tentativa de sanar o problema e resguardar os direitos humanos.

Entretanto, com o início do século XXI e o aumento dos conflitos entre nações, confrontos políticos e territoriais induziram ainda mais a migração forçada de milhões de pessoas, fomentando o debate e clamando por novos meios de proteção aos necessitados e também à proteção dos países que os recebem. Todavia, como já explícito, há ainda uma dificuldade quanto a modernizar o que fora tratado nestes três principais atos do século passado.

Neste ínterim, o Brasil, que por muitos anos se mostrou retrógado na questão do refúgio, tendo acolhido de forma tardia o Estatuto dos Refugiados de 1951, emergiu com um grande passo, tornando-se exemplo global no tema. Com a lei $\mathrm{n}$. 9.474 promulgada em 1997, renovando metodologias ultrapassadas e criando, por meios legais, métodos de proteção às pessoas que necessitam de ajuda e também esmiuçando normas para blindar o próprio país de irregularidades.

O status de país acolhedor é comprovado pelos dados do Ministério da Justiça implícitos anteriormente, que mostram que o número de solicitações de refúgio no Brasil vem aumentando a cada ano, sendo que no período de 2017 as solicitações enviadas ao CONARE (Comitê Nacional para os Refugiados) foram triplicadas comparadas com o ano anterior. Não obstante, apesar dos investimentos e novas políticas públicas para a proteção dos direitos humanos dos refugiados que solicitam entrada no país, certamente o fluxo de migrantes tende a aumentar progressivamente, fazendo com que o país necessite investir mais em novos programas de apoio, criações de novas e/ou modernizações de legislações já existentes, além de alianças fortalecidas com outras nações para que possa avançar socialmente na questão. 
Concluiu-se pelo observado nos fatos do período relatado, com base nos relatórios da ACNUR - Alto Comissariado da Organização das Nações Unidas para Refugiados e nos dispositivos legais pertinentes, principalmente no Estatuto do Refugiado (Lei n. 9474/97), que a hipótese resta confirmada, visto que o Brasil se consolida como destino de imigrantes em busca de sobrevivência. Contudo, apesar de ser mencionado como acolhedor, o país ainda precisa fortalecer as políticas públicas de abrigo e emprego para que a projeção de um fluxo cada vez maior não se transforme em crise.

Além disso, segundo dados extraídos do Alto Comissariado das Nações Unidas logo após 20 anos da promulgação da Lei 9474/97, esta continua sendo um modelo entre os marcos legais que se referem à proteção refugiados no mundo. $O$ recente desafio imposto ao Brasil é principalmente garantir que o sistema brasileiro de refúgio possa ser otimizado, principalmente no tocante ao processo de integração local de pessoas refugiadas.

\section{REFERÊNCIAS}

ACNUR. An introduction to international protection: protecting persons of concern to UNHCR. Geneva: Office of the United Nations High Commissioner for Refugees, 2005. Disponível em: <https://www.unhcr.org/3ae6bd5a0.pdf> Acesso em: 02 jan. 2019.

Conference of plenipotentiaries on the status of refugees and stateless persons: Summary Record of the Nineteenth Meeting. 2013. Disponível em: <https://www.unhcr.org/protection/travaux/3ae68cda4/conference-plenipotentiariesstatus-refugees-stateless-persons-summary.html>. Acesso em: 9 dez. 2018.

Conselhos e comitês no Brasil. 2019. Disponível em:

$\overline{<h t t p s: / / w w w . a c n u r . o r g / p o r t u g u e s / a c n u r-n o-b r a s i l / c o n s e l h o s-e-c o m i t e s-n o-b r a s i l />~}$ Acesso em: 01 set. 2019

Declaração do Brasil. 2014. Disponível em: <https://www.acnur.org/ fileadmin/Documentos/BDL/2014/9866.pdf > Acesso em: 21 ago. 2019.

Declaração de Cartagena. 1984. Disponível em: <https://www.acnur.org/ fileadmin/Documentos/portugues/BD_Legal/Instrumentos_Internacionais/Declaracao _de_Cartagena.pdf> Acesso em: 02 fev. 2019. 
Fridtjof Nansen. 2001-2018. Disponível em: <http://www.acnur.org/ portugues/campanhas-e-iniciativas/premio-nansen/fridtjof-nansen/>. Acesso em: 19 set. 2018.

Manual de procedimentos e critérios para a determinação de um refugiado. 2011. Disponível em: <http://www.acnur.org/portugues/wpcontent/uploads/2018/02/Manual_de_procedimentos_e_crit\%C3\%A9rios_para_a_de termina\%C3\%A7\%C3\%A3o_da_condi\%C3\%A7\%C3\% $\overline{\mathrm{A}} 30$ o_de_refugiado.pdf>. Acesso em: 18 set. 2018.

Refugiados. 2001-2018. Disponível em: <http://www.acnur.org/portugues/ quem-ajudamos/refugiados/>. Acesso em: 18 set. 2018.

. Refugiado ou Migrante? 2015. Disponível em: <https://www.acnur.org/ portugues/2015/10/01/refugiado-ou-migrante-o-acnur-incentiva-a-usar-o-termocorreto/ >. Acesso em: 11 set. 2019.

ALMEIDA, Guilherme Assis de. Direitos humanos e não-violência. 2 ed. São Paulo: Atlas, 2015.

BARICHELLO, Stefania Eugenia; ARAUJO, Luiz Ernani Bonesso de. Aspectos históricos da evolução e do reconhecimento internacional do status de refugiado. Universitas Relações Internacionais, Brasília, v.12, n. 2, p. 63-76, jul/dez, 2014. Disponível em: <https://www.publicacoesacademicas.uniceub.br/ relacoesinternacionais/article/viewFile/2997/2486 > Acesso em: 21 jan. 2019.

BRASIL. Lei n 9.474 de 22 de julho de 1997. Brasília, DF: Senado Federal, 1997. Disponível em: < http://www.planalto.gov.br/ccivil_03/LEIS/L9474.htm > Acesso em: 20 maio 2019.

Ministério da Justiça e Segurança Pública. Refúgio em números. Brasília, 2 ed. 2017. Disponível em: <https://www.justica.gov.br/seusdireitos/refugio/anexos/2deg-edicao-refugio-em-numeros-2010-2016-v-5-0final.pdf/view>. Acesso em: 20 ago. 2019.

. Ministério da Justiça e Segurança Pública. Refúgio em números. Brasília, 3 ed., 2018. Disponível em: <https://www.justica.gov.br/news/de-10-1-mil-refugiadosapenas-5-1-mil-continuam-no-brasil/refugio-em-numeros_1104.pdf>. Acesso em: 20 maio 2019.

. Ministério da Justiça e Segurança Pública. Resolução normativa do Comitê Nacional para os Refugiados $n^{\circ} 28$, de 20 de dezembro de 2018. Dispõe sobre a extinção do processo e regras de desarquivamento do processo de refúgio. Brasília. Disponível em: <https://www.justica.gov.br/seusdireitos/refugio/anexos/resolucao-normativa-do-comite-nacional-para-os-refugiadosno-28-de-20-de-dezembro-de-2018.pdf > Acesso em: 20 maio 2019. 
. Ministério da Justiça e Segurança Pública. Tabela com decisões sobre pedidos de reconhecimento da condição de refugiado - ACNUR (1993-1997) e CONARE (1998 a janeiro de 2019). Portal de Dados MJ. Disponível em: <https://www.justica.gov.br/seus-direitos/refugio/anexos/decisoes-conare-ate-jan2019.xlsx/view>. Acesso em: 21 jan. 2019.

. Ministério da Justiça e Segurança Pública. Visões do contexto migratório no Brasil. Brasília, 2017. Disponível em: <https://www.justica.gov.br/seusdireitos/refugio/anexos/visoes_do_contexto_migratorio_no_brasil.pdf/view>. Acesso em: 21 ago. 2019.

. Ministério das Relações Exteriores. Refúgio no Brasil. Portal Consular. Disponível em: <http://www.portalconsular.itamaraty.gov.br/refugio-no-brasil>. Acesso em: 20 maio 2019.

CARNEIRO, Wellington Pereira. A declaração de Cartagena de 1984 e os desafios da proteção internacional dos refugiados, 20 anos depois. Direitos humanos e refugiados, Dourados: Editora UFGD, 2012. Disponível em: <https://www.academia.edu/31073436/A_DECLARA\%C3\%87\%C3\%830_DE_CART AGENA DE 1984 E OS DESAFIOS DA PROTE $\%$ C3\%87\%C3\%830 INTËRNAC IONAL_DOS_REFŪGIADŌS_20_ANOS_DEPOIS_e_REFLEX\%C3\%95ĒS_SOBRE A_QUEST\%C3\%830_RACIAL_E_REFUGIO_NO_SISTEMA_BRASILEIRO>. Acesso em: 21 jan. 2019.

CARNEIRO, Wellington Pereira. O conceito de proteção no Brasil: o artigo 1 (1) da lei 9.474/97. Refúgio no Brasil: comentários à lei 9.474/97. São Paulo: Quartier Latin, 2017. Disponível em: <https://www.acnur.org/portugues/wpcontent/uploads/2018/02/Ref\%C3\%BAgio-no-Brasil-Coment\%C3\%A1rios-\%C3\%A0lei-9.474-97-2017.pdf>. Acesso em: 29 nov. 2018.

COMPARATO, Fábio Konder. A afirmação histórica dos direitos humanos.11. ed. São Paulo: Saraiva, 2017.

GUERRA, Sidney. Curso de direito internacional público. São Paulo: Saraiva, 2017. E-book.

GUERRA, Sidney. Direitos Humanos: na ordem jurídica internacional e reflexos na ordem constitucional brasileira. 2.ed. São Paulo: Altas, 2014.

GOODWIN-GILL, Guy. 2001. After the Cold War: Asylum and the Refugee Concept Move on. Forced Migration Review, Oxford, vol.10, p. 14-16. Disponível em: $<$ https://www.fmreview.org/sites/fmr/files/FMRdownloads/en/unhcr-convention50/goodwingill.pdf>. Acesso em: 25 set. 2018. 
GONZÁLEZ, Juan Carlos Murillo. A importância da lei brasileira de refúgio e suas contribuições regionais. Refúgio no Brasil: a proteção brasileira aos refugiados e seu impacto nas Américas. Brasília: ACNUR, 2010. Disponível em:

<https://www.acnur.org/portugues/wp-content/uploads/2018/02/Refúgio-no-Brasil_Aproteção-brasileira-aos-refugiados-e-seu-impacto-nas-Américas-2010.pdf>. Acesso em: 24 abr. 2019.

JUBILUT, Liliana Lyra; GODOY, Gabriel Gualano de. Refúgio no Brasil: comentários à lei 9.474/97. São Paulo: Quartier Latin, 2017. Disponível em: <https://www.acnur.org/portugues/wp-content/uploads/2018/02/Ref\%C3\%BAgio-noBrasil-Coment\%C3\%A1rios-\%C3\%A0-lei-9.474-97-2017.pdf>. Acesso em: 27 nov. 2018.

LAFER, Celso. A ONU e os direitos humanos. Estudos avançados, São Paulo, v. 9, n. 25, set./dez. 1995. Disponível em: <http://www.scielo.br/pdf/ea/v9n25/ v9n25a14.pdf>. Acesso em: 20 nov. 2018.

LEÃO, Renato Zerbini Ribeiro. O instituto do refúgio no Brasil após a criação do Comitê Nacional para os Refugiados - CONARE. 2005. Disponível em: <https://justica.gov.br/central-de-conteudo/estrangeiros/art_renatozerbini.pdf> Acesso em: 10 maio 2019.

LOPES, Brenner; AMARAL, Jefferson Ney; CALDAS, Ricardo Wahrendorff. Políticas públicas: conceitos e práticas. Belo Horizonte, Sebrae, 2008. Disponível em: <http://www.mp.ce.gov.br/nespeciais/promulher/manuais/MANUAL\%20DE\%20POLIT ICAS\%20PÚBLICAS.pdf > Acesso em: 20 ago. 2019.

MARQUEZ, Isabel. Refúgio no Brasil: comentários à lei 9.474/97. São Paulo: Quartier Latin, 2017. Disponível em: < https://www.acnur.org/portugues/wpcontent/uploads/2018/02/Ref\%C3\%BAgio-no-Brasil-Coment\%C3\%A1rios-\%C3\%A0lei-9.474-97-2017.pdf>. Acesso em: 27 nov. 2018.

MAZZUOLI, Valerio de Oliveira. Curso de direitos humanos. 5. ed. São Paulo: Método, 2018. E-book.

NAÇÕES UNIDAS NO BRASIL. A carta das Nações Unidas. São Francisco, 1945. Disponível em: < https://nacoesunidas.org/carta/>. Acesso em: 23 nov. 2018.

Qual a diferença entre 'refugiados' e 'migrantes'? 2016. Disponível em:

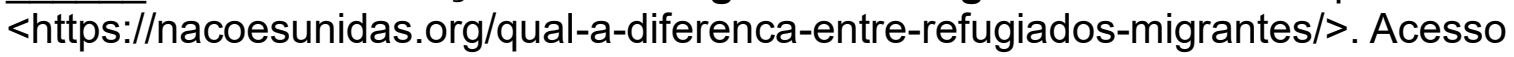
em: 18 set. 2018.

O que são os direitos humanos? 2016. Disponível em:

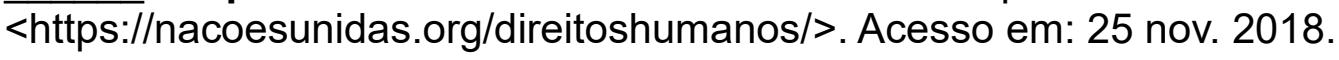

OLIVEIRA, Fabiano de Melo Gonçalves de. Direitos humanos. 1. ed. São Paulo: Método, 2016. E-book. 
ORGANIZAÇÃO DAS NAÇÕES UNIDAS. Convenção relativa ao Estatuto do Refugiados (1951). 1951. Disponível em: <https://www.acnur.org/fileadmin/ Documentos/portugues/BDL/Convencao_relativa_ao_Estatuto_dos_Refugiados.pdf> . Acesso em: 02 fev. 2019.

RAMOS, André de Carvalho. Curso de direitos humanos. 5 ed. São Paulo: Saraiva Educação, 2018.

REIS, Rossana Rocha; MOREIRA, Julia. Regime Internacional para refugiados: mudanças e desafios. Revista de Sociologia e Política, Curitiba, v.18, n. 37, out. 2010. Disponível em: <https://revistas.ufpr.br/rsp/article/view/31649/20176>. Acesso em: 24 set. 2018.

SCOTTINI, Alfredo. Dicionário da Língua Portuguesa. Alfredo Scottini (compilado), Blumenau: Todolivro Editora, 2009.

SILVA, Cesar Augusto Silva da; RODRIGUEZ, Viviane Mozine. Refugiados: os regimes internacionais de direitos humanos e a situação brasileira. Direitos humanos e refugiados, Dourados: Editora UFGD, 2012. Disponível em: <https://www.academia.edu/31073436/A_DECLARA\%C3\%87\%C3\%830_DE_CART AGENA DE 1984 E OS DESAFIOS DA PROTE $\%$ C3\%87\%C3\%830 INTERNAC IONAL DOS REFÜGIADŌS 20 ANOS DEPOIS E REFLEX\%C3\%95E S SOBRE A_QUEST\%C3\%830_RACIAL_E_REFUGIO_NO_SISTEMA_BRASILEIRO> Acesso em: 15 jun. 2019.

SOBREIRA, Fábio Tavares. Direito constitucional e direitos humanos. 1. ed. São Paulo: Saraiva, 2013. E-book.

UBER, Francielle. O Estado diante da questão dos refugiados. Direitos humanos e refugiados, Dourados: Editora UFGD, 2012. Disponível em: <https://www.academia.edu/31073436/A_DECLARA\%C3\%87\%C3\%830_DE_CART AGENA DE 1984 E OS DESAFIOS DA PROTE $\%$ C3\%87\%C3\%830 INTËRNAC IONAL DOS REFÜGIADOS 20_ANOS DEPOIS_e REFLEX\%C3\%95ËS_SOBRE A_QUEST\%C3\%830_RACIAL_E_REFUGIO_NO_SISTEMA_BRASILEIRO> Acesso em: 15 jun. 2019.

Artigo recebido em: 24/09/2019

Artigo aceito em: 01/11/2019

Artigo publicado em: 16/12/2019 